\title{
LEITURA E PRODUÇÃO DE TEXTOS : TEORIAS E PRÁTICAS NA SALA DE AULA
}

\author{
Rita Maria Diniz Zozzoli \\ Programa de Pós-Graduação em Letras \\ Universidade Federal de Alagoas
}

\section{INTRODUÇÃO}

Tema multidisciplinar, a leitura vem sendo, há algumas décadas, objeto de grande número de formalização de modelos teóricos e de realização de investigações em diversas áreas do conhecimento, a tal ponto que se poderia até considerar que há pouco a ser explorado sobre o assunto. Apesar disso, através das observações de pesquisa', da experiência prática em sala de aula e do diálogo com alunos e professores de diferentes graus, este texto parte da constatação de que ainda há muito a refletir sobre a questão, quando se elege a sala de aula como centro da observação dos fenômenos e quando se pretende ir além da visão de leitura como simples prática escolar.

Quanto à produção, é relativamente recente a preocupação com a escrita escolar, numa perspectiva em que o aluno seja considerado autor de textos, apesar de o tema da escrita e da reescrita já constarem, há bastante tempo, dos objetivos de modelos teóricos e pesquisas também situados em várias áreas do conhecimento. Também não é muito antiga a discussão sobre a necessidade de interligação entre as práticas de leitura e de escrita na sala de aula, questão ainda menos explorada no quotidiano das situações de ensino e aprendizagem.

Título da pesquisa coordenada pela autora do artigo e desenvolvida em equipe no Grupo de Trabalho Ensino e Aprendizagem de Linguas, do Programa de Pós-Graduação em Letras-UFAL: Leitura e produçào de texto na sala de aula de linguas: a constituição de uma gramática do aluno. Financiamento: PIBIC-CNPq 
Sem objetivar um relato histórico exaustivo, cronologicamente organizado sobre as diversas propostas teóricas e suas implicações nas práticas escolares, busca-se neste artigo examinar alguns dos posicionamentos teóricos mais representativos das práticas observadas em situações de pesquisa em sala de aula. Saliente-se que nessas constatações não se parte de uma visão dicotômica entre teoria e prática, em que a primeira determinaria as situações de aplicação que funcionariam ou não dentro das previsões do modelo escolhido, mas de uma visão em que as relações entre teoria e prática são de interdependência. Aliás, pelo que se observa das situações examinadas, mesmo que se pretenda adotar um modelo teórico determiriado a priori, o que se efetiva na prática nunca corresponderá à simples aplicação desse modelo, uma vez que a sala de aula, como afirma Kramsch $(1991: 8)^{2}$,

(...) com sua variedade de 'discurso', sua rede complexa de interações entre o professor e o grupo e entre cada um dos membros do grupo, suas relações de força e suas esferas de influência, a multiplicidade de suas intenções e de suas percepções, seus imperativos didáticos e seus compromissos pessoais, é um microcosmo (...).

\section{LEITURA: POSICIONAMENTOS TEÓRICO-PRÁTICOS ${ }^{3}$}

Numa primeira tentativa de análise, num plano bastante amplo e abrangente, constatam-se quatro tipos básicos de posicionamentos teórico-práticos ${ }^{4}$ :

Todas as traduções dos originais em francês foram feitas pela autora do presente artigo.

Os posicionamentos aqui apresentados limitam-se, sem pretensão de exaustividade, ao campo de estudos da Linguagem e da Lingüistica, não contemplando, portanto, outras áreas de conhecimento como a Antropologia, a Filosofia, a Historia e outras que, não obstante. apresentam diversos estudos sobre o tema da Leitura.

Existem combinaçòes entre esses tipos básicos compativeis, dependendo da linha de trabalho dos autores, como é o caso da articulação entre as teorias Psicolingiísticas, que envolvem os processos mentais e o conhecimento prévio e também os pressupostos da Lingüística textual. por exemplo. 
(1) os que centram a compreensão no sujeito;

(2) os que centram a compreensão na materialidade lingüística;

(3) os que centram a compreensão na enunciação;

(4) os que centram a compreensão nos aspectos históricosociais.

Porém, quando se objetiva uma análise mais aprofundada, tal classificação é excessivamente abrangente, para dar conta da multiplicidade de modelos e tratamentos encontrados em pesquisas e em situações de ensino e aprendizagem, como veremos a seguir.

Partindo do sujeito como categoria central - posicionamento (1) -, poderemos ter tanto o subjetivismo idealista criticado por Bakhtin (1981:72-77), que representaria uma visão de leitura como identificação do pensamento do autor, como os modelos mais recentes da Psicolingüistica, que, apesar de centrados no sujeito, não seguem a mesma visão. Como ponto comum, constata-se que esses modelos partem de uma descrição de fenômenos essencialmente subjetivos, incluindo, no máximo, uma visão interativa centrada no sujeito ou nas relações imediatas entre sujeitos, mesmo quando considerados mais completos, por envolverem o conhecimento prévio do leitor, como o modelo de Rumelhart \& Ortony ou 0 de Schank \& Abelson $^{5}$, (apud Cavalcanti, 1989: 43-48). Entretanto, é necessário reconhecer que, por incluirem noções como conhecimento prévio, esses modelos mais recentes, mesmo centrados no sujeito, não contêm a mesma visão de subjetivismo idealista já citada.

No posicionamento (2), ter-se-ia desde a concepção mais antiga de leitura linear (muito presente ainda nas salas de aula), que enfoca a identificação de unidades lingüisticas localizadas na palavra e na frase até as concepções estruturalistas mais recentes, as de orientação ckomskyanas, as da Lingüística Textual e as pós-estruturalistas, desde que enfatizem a materialidade lingüistica. Como no caso de (1), é útil lembrar que as linhas teóricas acima mencionadas

Esse último modelo, além disso, prevè a noçào de crenças. 
representam tendências e estágios distintos da evolução da Lingüística. Não é possivel confundir a visão linear de bases históricas mais antigas com as visões mais recentes, como as da Lingüistica Textual, por exemplo.

No posicionamento (3), estariam os estudos que propõem ultrapassar os limites do lingüístico, focalizando a enunciação, dentro dos quais podem ser incluidas, por exemplo, linhas teóricas desde Benveniste até as de seguidores de Culioli, de Ducrot, de Greimas, de Pierce, Austin ou de Searle, ou outros estudos de diversas linhas da semiótica ou da pragmática. Como nos itens anteriores, tais linhas teóricas são muito distintas, o que implica diferenças inclusive na própria visão de enunciação. Por exemplo, Bertrand (in Greimas \& Courtés, 1986: 75 - verbete Énonciation) chama a atenção para as diferenças de conceito de enunciação entre a abordagem lógico-semântica dos fenômenos discursivos de Ducrot, que se fundamenta numa "concepção enunciativa do sentido", e a teoria das "operações enunciativas" de Culioli, que visa à descrição formal da atividade de linguagem.

No posicionamento (4), classificar-se-iam as tendências sócio-históricas, de origem marxianas, ligadas à análise do discurso (AD) ou nãc. Da mesma forma, aqui se estabelecem diferenças, como, por exemplo, entre seguidores de Pêcheux e Foucault e outros que se fundamentam principalmente em Bakhtin. A esse respeito, observe-se que a visão de sujeito assujeitado defendida pelos primeiros não é compartilhada nos mesmos termos pelos que trabalham com a visão Bakhtiniana (cf. visões de sujeito analisadas mais adiante neste texto).

É óbvio que as tendências inseridas nessa primeira tentativa de classificação reúnem posições muito distintas em suas propostas, por fazerem parte de paradigmas muito diferentes entre si e que não são, portanto, abordáveis em conjunto. Não é possível igualar, num mesmo plano de contribuição para os estudos da linguagem, as visões mais simplistas de certos posicionamentos a visões mais complexas e bem formalizadas de modelos da Psicolingüística ou da Lingüistica Textual, por exemplo. Conclui-se, desse modo, que 
a classificação acima serve principalmente, num primeiro momento, para obter uma visão global da complexidade do tema examinado, considerando-se apenas 0 foco da compreensão. Num segundo momento, essa classificação será útil para tentar refletir sobre como, na sala de aula, é mais fácil para o professor em processo de formação passar de forma consciente de um modelo para outro dentro do mesmo posicionamento ou dentro de posicionamentos conjugáveis (1) e (2),$-{ }^{6}$ do que passar para paradigmas opostos como, por exemplo, do posicionamento de tipo (1) para o posicionamento de tipo (4). Isso se dá por causa das concepções de língua/linguagem e de sujeito que estão em jogo nos posicionamentos. Essas concepções, relacionadas a seguir, de forma bastante sucinta, correspondem a raízes ideológicas mais profundas que envolvem as escolhas politicas do professor.

\section{CONCEPÇÕES DE SUJEITO, LINGUAGEM E LEITURA}

A classificação apresentada abaixo, mesmo que não leve em conta nuanças e desdobramentos de posições, decorrente da multiplicidade de modelos teóricos existentes, representa uma tentativa de distinguir concepções que estão na base de posicionamentos teóricos e práticos encontrados nas situações de sala de aula:

(a)concepções de sujeito individualista (cf. critica de Bakhtin ao subjetivismo idealista, 1981, passim) e de linguagem como expressão do pensamento, que dão origem às visões de leitura como reconhecimento do pensamento do autor, através do reconhecimento (decodificação) de unidades lingüísticas isoladas, localizadas na palavra e na frase. Essas unidades lingüisticas são reduzidas a uma correspondência com o pensamento;

(b) concepções de sujeito racionalista (cf. crítica de Bakhtin ao objetivismo abstrato, op. cit., passim) e de lingua como objeto isolável para estudo, sem incorporar as imprevisões do discurso. Tais concepções dão origem às visões de

Cf. (icurel (1990) como um exemplo de conjugaçào dos posicionamentos (1) e (2) 
leitura centrada em elementos lingüísticos frasais (Lingüistica anterior a Chomsky) ou elementos suprasentenciais ou macro-textuais (Lingüistica chomskyana e certos estudos da Lingüística Textual), ou ainda a visões de leitura através de estudos psicolingüisticos que seguem essa visão de sujeito racionalista;

(c) concepções de sujeito assujeitado pelas determinações histórico-sociais e de linguagem também determinada pelas formações ideológicas e discursivas (Foucault e seus seguidores), que estão na base das propostas de leitura que preconizam a completa subordinação da materialidade lingüística à sua exterioridade;

(d)concepção de sujeito "relacional" (Galissot, 1991) ou de sujeito "do conhecimento e da subjetividade" (Lantz, 1991), dentro de uma teoria que procura conciliar uma teoria social com uma teoria do sujeito. Tal visão de sujeito não assujeitado, nem pelo determinismo racional, nem pelo determinismo histórico-social e que não é tampouco individualista, apesar de pouco difundida, é compatível tanto com algumas concepções de linguagem oriundas de teorias da enunciação, como na análise do discurso de linha não foucaultiana. A visão de linguagem, nesse caso, tanto permite uma conciliação entre a dimensão previsivel (linguagem enquanto regras e categorias organizadas) e a não previsível (representada pelas oscilações discursivas), como a conciliação entre a dimensão psicológica e a dimensão histórico-social (cf. definição de linguagem de Maingueneau, 1995: 6). A leitura, conseqüentemente, poderá ser compreendida, como na pesquisa coordenada pela autora deste artigo, como produção de sentidos ao mesmo tempo coletiva e subjetiva. Seguindo o pensamento de Galissot (op. cit.: 16) de que a questão de fundo de uma teoria do sujeito é a questão da autonomia, que esse autor procura definir através da "esperança/utopia de emancipação social e pessoal", a pesquisa citada propõe, entre outros objetivos, refletir sobre a autonomia do aluno leitor/produtor de textos. Mais precisamente, procura-se investigar como se constitui a gramática desse aluno e como ela contribui (ou não) para essa autonomia. 


\section{LEITURA E PRODUÇÃO: UMA VISÃO DE PROCESSO}

Se considerarmos o processo da leitura em toda a sua complexidade, observaremos que dificilmente diferentes perspectivas podem ser desprezadas, sem que se obtenha uma redução do fenômeno. É óbvio que os modelos teóricos, por motivo de um determinado rigor científico, prefiram operar recortes e neles procurem se aprofundar. Porém, mesmo diante da impossibilidade de se trabalhar com igual profundidade nas múltiplas facetas do fenômeno, e, diante da necessidade de se operar escolhas paradigmáticas predominantes, é lícito considerar que estudos que privilegiam uma única perspectiva (seja ela lingüística, psicolingüística, enunciativa ou histórico-social) não esgotam uma questão tão complexa, principalmente quando o objetivo é se trabalhar o processo como um todo, dentro de uma formação de leitores e produtores de textos para agir no mundo, para ser cidadãos, através de suas ações.

Explicando melhor, trata-se de um processo de natureza complexa dentro de uma situação igualmente complexa, que é a da sala de aula de lingua.

\subsection{O processo}

Quanto ao processo de leitura e de produção, diante da necessidade de ampliar essa visão, pode-se propor o diagrama apresentado a seguir. Neste diagrama, parte-se da adaptação de alguns conceitos de Coste (1988: 15), sem, entretanto, adotar sua concepção de competência comunicativa de leitura e indo mais além no que esse autor considera "componentes dessa competência". O termo "componentes", de Coste, foi substituído pelo termo elementos no diagrama, uma vez que "componentes" diz respeito a um paradigma que se limitaria à competência de comunicação do sujeito e ao ato imediato de leitura e que não corresponde à visão aqui exposta. Neste diagrama, elementos não existem apenas em função do leitor e da leitura, mas também em função do autor e da produção; são, portanto, os elementos que entram em jogo no processo que envolve produção e leitura. É necessário esclarecer a 
terminologia extraida de Coste após as reformulações efetuadas para este trabalho: os elementos de organização textual correspondem à interligação entre os elementos frásticos e transfrásticos; os elementos lingüísticos, aos elementos referentes à lingua em questão $e$ seu funcionamento; os elementos referenciais, aos elementos do texto relacionados aos domínios de experiência e conhecimento; os elementos relacionais, aos elementos que se referem ao regulamento de trocas interpessoais em função das posições, dos papéis e das intenções dos interlocutores; os elementos situacionais, aos elementos que se referem à situação imediata, às circunstâncias de produção do texto e da leitura.

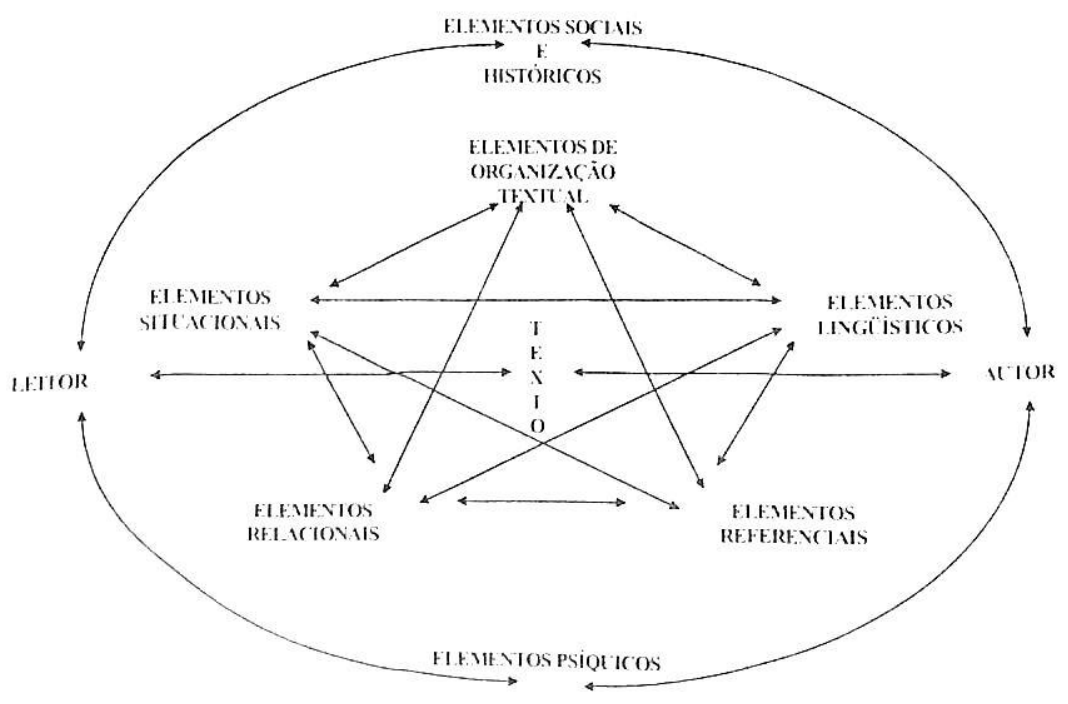

\section{LEITURA E PRODUÇÃO}

O diagrama procura visualizar o processo como um todo, compreendendo ao mesmo tempo leitura e produção e inserindo o processo que corresponde à situação mais imediata (circuito menor) dentro de um plano menos imediato e mais amplo, constituido de elementos psiquicos e históricosociais (circuito maior). 


\subsection{A sala de aula}

Quanto à sala de aula de língua, vale salientar que se tem ao mesmo tempo uma situação em que se usa a linguagem para as diferentes trocas dentro da própria situação de aula (Bom dia, professor; prestem atenção, meninos, por exemplo) e também se usa a linguagem como objeto de trabalho, em situações de reflexão ou de simulação, com objetivos de aprendizagem. Cicurel, em 1985, já explicava bem essa dupla utilização da linguagem na sala de aula de língua, dizendo: "o objeto a aprender é a lingua e o meio para chegar a isso é igualmente a língua" (op. cit. p. 15). Em livro mais recente (1990), a mesma autora explora mais o que chama de "dimensão 'ficcional' da comunicação didática", na qual "para explicar, elucidar o sentido, dar um contexto, os participantes recorrem a situações ficticias" (op. cit. p. 51).

É claro que na aula de língua estrangeira a "dimensão ficcional" está mais presente, já pelo próprio fato da "artificialidade" de se falar ou escrever em lingua estrangeira em contexto específico para se fazer isso, enquanto que fora dali, essa língua não vai ser utilizada ou, quando muito, só vai ser utilizada em determinadas situações. Mas também no caso da língua materna, muitas das práticas mais tradicionais utilizadas em sala de aula tratam essa lingua por assim dizer como estrangeira. Essa crítica já foi feita por Bakhtin (1981: 90109), tanto a respeito do tratamento dado à língua por determinados modelos lingüisticos, como também, em alguns momentos, a respeito desse mesmo tratamento no ensino de linguas.

Para esclarecer melhor, citemos os exemplos de exercícios de gramática ou vocabulário destacados de contextos situacionais. Esses exercicios tanto podem ter como base modelos prescritivos tradicionais, com aplicação explicita de regras da gramática normativa, como podem utilizar a abordagem indutiva dos exercicios estruturais, ou ainda mais recentemente, podem utilizar a abordagem nocional-funcional. O que eles têm em comum é que desvinculam a lingua de um contexto de uso, o que acarreta apresentá-la como objeto a ser decodificado, memorizado. O mesmo acontece na leitura, quando se propõe "decifrar" um texto, apenas através do 
reconhecimento de unidades lingüisticas. Mesmo em lingua materna, e mesmo quando se tenta dar uma dimensão de uso ficcional, muitas vezes esse uso é induzido de forma tão diretiva e tão desvinculada da realidade de fora da sala de aula que se contribui de qualquer forma para uma idéia de que a língua da escola é outra, diferente da que se utiliza fora dela.

\section{O TRABALHO COM A LEITURA E A PRODUÇÃO DE TEXTOS EM SALA DE AULA}

A relação entre os modelos e o trabalho com a leitura e a produção em sala de aula, como já foi salientado, não é de biunivocidade. Entretanto, a influência das propostas teóricas é inegável, mesmo quando ela não é estabelecida de forma consciente pelos professores que as utilizam. Quando o professor não participa de nenhum processo de formação continuada, torna-se muito difícil para ele identificar os diferentes paradigmas e, mais ainda, relacioná-los com sua prática, operando escolhas. Muitas vezes torna-se mais fácil adotar a proposta de um livro didático ou receber alguma receita pronta de algum estágio de formação. É claro que tanto - livro como a receita seguem pressupostos teóricos que, na maioria das vezes, o professor ou desconhece ou apenas conhece parcial e insuficientemente. Diante dessa dependência de algo pronto, às vezes o professor passa de um posicionamento para outro, em alguns casos até não conciliáveis entre si. Para o processo de aprendizagem, talvez tão prejudicial quanto essa hesitação, é o fato de acreditar que tal modelo ou tal abordagem será a panacéia e que sua aplicação garantirá sucesso. Tais atitudes continuam sendo freqüentes nas situações de ensino e aprendizagem nos diversos graus.

Os objetivos de atividades com a leitura em sala de aula de lingua diferem de acordo com os objetivos de ensino e aprendizagem. Como a visão de ensino mais comum ainda é a de transmissão de conhecimentos, a leitura vai servir muito freqüentemente ao objetivo principal dessa transmissão de conhecimentos e de avaliação dessa transmissão. Servindo a esse duplo objetivo, o que vai variar são os tipos de 
conhecimentos que vão ser introduzidos de acordo com as linhas teóricas subjacentes. É interessante observar que a adoção de linhas recentes da Lingüística e da Psicolingüística não implica necessariamente a atualização do modelo de ensino e que em muitos casos permanece-se fiel ao duplo objetivo acima mencionado.

Geraldi (1984: 85 e 1993:173-174) nos fala do pretexto da leitura, levantando a discussão sobre para quem o pretexto serve (professor ou aluno) e também sobre o tipo de pretexto, que inclusive pode não ser o de transmissão de conteúdo (o texto como pretexto para a produção de outro texto ou para dramatizações, ilustrações, desenhos etc.). Concordando com Geraldi e visando acrescentar uma contribuição para a compreensão da utilização da leitura/ produção de textos na sala de aula, no presente trabalho far-se-á a distinção entre pretexto, que corresponderá aqui a uma sub-utilização do texto, com objetivo principal (e às vezes único) de transmissão de algum conteúdo e sua posterior avaliação, e o trabalho de leitura integrado a atividades de reflexão e de produção. Com base nessas distinções, é possivel destacar:

\subsection{Leitura com o objetivo de transmissão de conteúdos e posterior avaliação / produção com o objetivo de reproduzir conhecimentos e posterior avaliação}

\section{ATIVIDADES ${ }^{7}$ COM O TEXTO OU A PARTIR DELE:}

5.1.1. Leitura em voz alta, com observação de correção de conteúdos fonológicos (pronúncia correta das palavras, com base na pronúncia culta, observância das pausas, do ritmo e da entonação)

Dentro de uma visão de sujeito, de linguagem e de leitura de tipo (a) ou de tipo (b), nos modelos estruturais dos primórdios da Lingüistica, que favorecem a leitura linear, por se localizarem no plano da palavra e da frase (cf. concepções já referidas anteriormente), geralmente se pretende que essa

\footnotetext{
O termo atividades tem aqui um signilicado genérico, abrangendo tanto as atividades mais dirigidas e fechadas, como os exercicios mais lladicionais, como tambem as atividades menos dirigidas em que há espaço para a criatividade.
} 
tarefa acarretará em boa pronúncia e/ou melhor compreensão para o aluno. Quando preenche o objetivo de avaliação de compreensão do aluno, essa atividade é adequadamente criticada por Kleiman (1993: 21-22). É útil observar que, mesmo quando não se objetiva a avaliação da compreensão, o tratamento dos conteúdos fonológicos por si mesmos, enquanto conteúdos desvinculados de qualquer outro objetivo de uso da língua, além de dificultarem o processo ao aumentarem a carga cognitiva, propiciam problemas afetivos com a leitura (idem, ibid).

\subsubsection{Questionários de "compreensão" orais e/ou escritos}

Em muitas situações de sala de aula, tais questionários correspondem a uma visão de leitura como reconhecimento de sentidos e de formas lingüisticas. Tal reconhecimento corresponde ao objetivo de "encontrar as idéias do autor", que se postula como sentidos únicos, geralmente já preestabelecidos pelo professor e/ou livro didático ou então visa-se ao reconhecimento de formas lingüisticas consideradas num plano linear. Por isso, a maior parte das perguntas formuladas não são $a b e r t a s^{8}$ e conduzem quase sempre ao tipo de resposta pretendida pelo professor e/ou livro didático. Ao direcionarem dessa forma a compreensäo, muitas vezes até apontam os lugares dos textos a serem considerados para determinada resposta. Geralmente pretende-se que a tarefa repetida de reconhecimento em vários textos acabe se transformando em conhecimento para o aluno. Essas práticas correspondem às concepçöes de sujeito, linguagem e leitura de tipo (a) ou de tipo (b) - modelos estruturalistas que se limitam ao plano da palavra e da frase, como no item anterior.

A essas práticas das atividades de tipo 5.1.1. e 5.1.2. subjaz a idéia que de Certeau (1990: 261) encontra na Ideologia das Luzes e denuncia ainda na época atual: "com mais ou menos resistência, o público é moldado pelo escrito (verbal ou icônico), torna-se semelhante ao que recebe, enfim, deixa-se imprimir pelo texto e como o texto que lhe é imposto".

Perguntas que nào sugerem uma única resposta, não remetem a partes do texto já identificáveis na própria pergunta, por exemplo. 
Em outras palavras, citando Bakhtin (1981: 99), trata-se da compreensão como ato passivo, "que exclui de antemão e por príncipio qualquer réplica ativa". Muitos trabalhos já foram feitos para analisar a qualidade de perguntas e respostas desses questionários, mas, para efeito de aprendizagem, além das tipologias, o que parece ser mais significativo é o fato de a pergunta direcionar mais ou menos a compreensão (perguntas abertas, apenas para instigar o diálogo, correspondem a uma atitude menos autoritária, por exemplo), é o espaço gerado para respostas diferentes e até destoantes, e, principalmente, é a existência de um espaço para perguntas e comentários dos próprios alunos.

5.1.3. Exercícios de diversas formas ${ }^{9}$, para explorar conteúdos lingüisticos lexicais ou gramaticais encontrados no texto e apresentados em frases, de forma desvinculada de situações de uso, mesmo fictícias

Tais conteúdos são considerados como objeto final da aprendizagem. Da mesma forma que nas atividades anteriores, aposta-se na identificação, repetição e memorização de conteúdos sob diferentes formas que garantiriam a aprendizagem da língua - cf. concepções de sujeito, linguagem e leitura de tipo (a) e certos modelos estruturais contidos em (b). É freqüente encontrar-se a alegação por parte de professores e/ou de manuais de que esse trabalho com unidades lexicais ou gramaticais "é feito a partir do texto" e não de frases isoladas. Entretanto é necessário alertar para o fato de que o trabalho feito com esses exercícios não acontece dentro do texto que é estudado, nem dentro de outros textos apresentados a partir de um texto de base, nem a partir de textos dos alunos; é realmente um trabalho executado à parte. fora do texto, e mesmo que utilize formas desse texto, essa utilização se dá através de frases ou expressões isoladas.

Como já foi observado em parágrafo anterior sobre a sala de aula, tais exercicios podem seguir paradigmas teóricos diversos, desde a visão prescritivo-normativa até visões mais

Os exercicios com frases mais commus são os de preenchimento de lacunas e os de múltipla escolha. Os que pressupoem alguma ransformaçào da trase sào menos frequïcntes. 
recentes como, por exemplo, semântico-estruturais, com exercícios que visam à localização de unidades lingüísticas na frase (para explicitar melhor, cite-se o caso de exercicios que, através de lacunas ou múltipla escolha, tratam do emprego de vários tipos de artigos em frases soltas), até visões nocionais/funcionais, com exercícios que enfocam determinada noção, como a quantidade, por exemplo, mas fazem isso também com frases soltas.

Uma análise mais aprofundada dos tipos de exercícios, seus objetivos e contribuições para a aprendizagem, incluindo aqueles que seguem linhas teóricas mais atuais, ainda é necessária, pois geralmente as críticas sobre os exercicios visam quase sempre àqueles de gramática dita tradicional e mais uma vez não levam em conta que a questão não está apenas na escolha do paradigma teórico, mas também na forma de se trabalhar com a língua em sala de aula. Entretanto, para não extrapolar o tema central desse artigo, essa questão não será aqui explorada. Ela já é objeto de outros trabalhos a serem publicados, com foco específico na gramática.

5.1.4. Atividades com modelos de macro-estruturas textuais

De uso mais recente e decorrente das contribuiçōes da Lingüistica Textual, tem-se as atividades com modelos de macro-estruturas textuais que, portanto, estão apoiadas em modelos que ultrapassam o nivel da frase, nas concepções de sujeito, linguagem e leitura de tipo (b). São trabalhos de elaboração de textos a partir de modelos textuais, em que o aluno reproduz a macro-estrutura do texto de base. Geralmente, na base dessas atividades, estão as tipologias textuais que orientam sobre as diferenças de macro-estrutura. Segundo Péry-Woodley (1993:98-99), talvez a tipologia mais utilizada no ensino de linguas seja aquela originada da retórica, que distingue quatro grandes tipos: narrativo, descritivo, expositivo, argumentativo. Mas há grande variedade de tipologias, segundo os diferentes autores que exploram essa questäo (cf. id::94-103). 
Mais uma vez é útil salientar que não é a escolha da linha teórica lingüística que garante por si só que o tratamento da questão em sala de aula se afaste da visão de transmissão de conhecimento. Foram observadas situações de sala de aula em que os modelos macro-textuais são usados de forma diretiva: o professor apresenta o modelo a ser seguido e os alunos devem imitá-lo, sem que haja abertura para discussão, nem no momento da apresentação do modelo, nem no momento da execução da atividade e tampouco na ocasião da correção. Essa questão, também por sua relevância, como a apresentada no item anterior, merece ser objeto de trabalho específico.

5.1.5. Reconhecimento de informações sobre estilos, escolas de época e biografia de autores

Essa atividade é encontrada em muitas aulas de literatura, mas também em aulas de lingua que utilizam o texto literário. É freqüente que o texto literário escolhido seja apenas o canônico, ou seja, texto considerado literário pelos padrões da teoria literária e da crítica (Lajolo, 1988: 87-99). Quando a atividade se reduz ao reconhecimento supracitado, sem propiciar outro tipo de experiência com o fenômeno literário, geralmente tem-se como base a mesma idéia subjacente de que tais informações contribuirão para moldar o leitor, como já foi mencionado em 5.1.2., com apoio em de Certeau (1990). Conseqüentemente, tem-se as concepções de sujeito, linguagem e leitura de tipo (a), aliadas, em alguns casos a concepções de tipo (b) que visam à correção formal no plano da palavra e da frase. A diferença, nesse caso, não seria apenas a correção da lingua o foco principal da "moldagem", mas também o estilo e, ainda recorrendo mais uma vez a Lajolo (op. cit.: 96), a educação do gosto.

Cabe ainda lembrar que a utilização da leitura ultrapassa o âmbito da sala de aula de língua, estando presente nas aulas de todas as disciplinas com menor ou maior freqüência. Os tratamentos em geral correspondem a uma visão de leitura como reconhecimento, objetivando a memorização de conteúdos específicos da disciplina, 
geralmente explorados através do questionário de compreensão supracitado que, nesse caso, dirige a leitura em função desse objetivo de transmissão de conhecimentos memorizáveis.

\subsection{Leitura integrada à produção e à reflexão sobre a lingua/linguagem}

A diferença básica entre essas atividades e as mencionadas em 5.1 é que o texto não é aqui considerado como mero instrumento de transmissão e avaliação de conteúdos, e que as concepções de sujeito, linguagem e leitura correspondem, segundo a postura do professor e as ações executadas em sala de aula, às visões contidas em (c) e (d).

\section{ATIVIDADES COM O TEXTO OU A PARTIR DELE:}

5.2.1. Atividades que incluem a interação entre professor/alunos e alunos entre si, na compreensão, na produção e na reflexão sobre a língua ou a linguagem

Essas atividades procuram situar a discussão sobre o texto lido ou produzido, ou sobre questões de língua/linguagem, de forma não centrada no professor, que, entretanto, permanece com o papel de orientar e fomentar o debate e fornecer subsidios quando necessário. Muito defendida atualmente pela maior parte das correntes teóricas e por todos os estágios de formação, esse tipo de prática, que é a proposta mais eficiente para que se instale uma certa autonomia de leitura e produção no aluno, tem encontrado obstáculos na realidade da sala de aula. Através de observações de pesquisa e de contatos com professores em formação, observa-se que, por um lado, o professor, por sua formação e sua experiência, tem dificuldades em libertar-se de uma postura diretiva e, por outro lado, os alunos, pelas mesmas razões, também têm dificuldade em abandonar a atitude passiva mas confortável em que se encontram. Junto a isso, em certos casos, o número excessivo de alunos em cada turma (40 ou mais em algumas turmas do ensino público) ainda aumenta os entraves para um trabalho dito interativo. 
Diante desse contexto, é cabivel postular que só se conseguirá alguma mudança significativa em grande escala através de uma ampla transformação na instituição escolar como um todo, incluindo necessária e prioritariamente a formação continuada de professores e do quadro técnicoadministrativo, sem falar na reformulação de toda a concepção de currículo, programas, materiais pedagógicos, avaliação (na qual estão incluídos os concursos, como o vestibular, por exemplo, que em muitos casos continuam apenas medindo a memorização de conteúdos), entre outros;

5.2.2. Atividades que estabeleçam interligação entre a sala de aula e o contexto social mais imediato (da escola) e o mais amplo (de fora da escola: da comunidade, do bairro, da cidade, do país, do mundo)

Geraldi (1993:16) alerta para a necessidade de produzir "textos na escola e não para a escola". Tanto a leitura como a produção, na perspectiva de formação do leitor para agir no mundo, defendida no início deste trabalho, devem privilegiar essa interligação com o contexto social. É necessário, entretanto, ponderar que essa ligação com o mundo, quando não executada através de ações precisas (escrever uma carta reivindicando algo à prefeitura e efetivamente enviar essa carta, por exemplo), possa ser realizada através dos próprios temas e textos escolhidos e produzidos e da discussão que se instala na sala de aula.

É útil considerar que, dentro do contexto escolar, nem sempre é viável tornar todas as produções diretamente utilizáveis na realidade de fora da sala de aula ou da escola. A dimensão ficcional, já abordada anteriormente, mesmo quando recusada e negada, de qualquer modo se faz presente, porque é inerente à situação. Pode-se inclusive pretender que ela não é necessariamente nefasta à aprendizagem. Dependendo do tipo de interação que se instala na sala de aula, a produção de um texto literário por um aluno, por exemplo, mesmo que não venha a sair daquele quadro, indo no máximo até o jogral ou o mural da escola, ou mesmo que nem isso aconteça, pode representar para esse aluno uma experiência de interação com os outros sujeitos na sala de aula e uma experiência 
transformadora em suas perspectivas de ver o mundo e de se expressar diante dele. Essa experiência certamente não poderá ser considerada no mesmo plano que uma produçãoimitação, imposta e direcionada, obtida em outras circunstâncias.

5.2.3. Atividades que integram as modalidades oral e escrita, as habilidades e também diferenças de registros

A separação entre as modalidades e habilidades correspondem a uma visão que não só desconsidera a interligação entre as modalidades dentro do uso da língua, mas também comumente estabelece hierarquia na aprendizagem. Em lingua estrangeira, a hierarquia entre as modalidades (oralidade e escrita) e habilidades (compreensão e expressão) é mais presente e ainda muito adotada nas práticas de sala de aula: primeiro se ouve, depois se fala, em seguida se lê e por último se escreve. Mesmo "em língua materna, ainda é bastante comum aceitar-se a idéia de que é preciso "dominar" a língua (o que geralmente significa falar de acordo com as regras da norma culta) segundo alguns ou, no dizer de outros, atingir determinada "competência lingüística", para poder escrever. Marcuschi (1997: 41) atesta: "a visão monolitica da língua leva a postular um dialeto de fala padrão calcado na escrita, sem maior atenção para as relações de influências múltiplas entre fala e escrita".

$\mathrm{Na}$ pesquisa supracitada em língua materna e língua estrangeira, constata-se que a interligação entre as modalidades e habilidades, na proposta de intervenção na sala de aula, permite vivenciar a lingua de forma que ela não se apresente ao aluno como objeto pronto a ser explorado de forma fragmentada; em outras palavras, não seja considerada como "língua morta", como critica Bakhtin. Diz esse autor, quando fala em ensino de LE: "a palavra isolada de seu contexto, inscrita num caderno e apreendida por associação com seu eqüivalente em russo, torna-se, por assim dizer, sinal, torna-se uma coisa única e, no processo de compreensão, o fator de reconhecimento adquire um peso muito forte" (Bakhtin, 1981: 95). Se bem que com peso menos forte, porque o aluno já utiliza a língua no seu cotidiano, esse reconhecimento 
persiste em língua materna quando se adota a visão fragmentada dos conteúdos no ensino.

Quanto aos registros, muitos autores já falaram sobre a falta de integração entre eles e a chamada norma culta padrão. Mas ainda é necessário pensar em maneiras de integrar, através de atividades e da própria postura do professor na sala de aula, essa norma padrão e os registros que os alunos trazem de suas comunidades.

Falando de plurilingüismo, Dabène (1994: 153-165) aconselha uma "integração do repertório comunicativo dos alunos" e um "nova concepção da programação". Suas sugestões, mesmo que destinadas ao ensino plurilingüe, como chegam até ao nivel de atividades, podem servir de exemplo para o tratamento de diferenças de registros dentro de uma mesma língua. Essa mesma autora chama a atenção para o fato que a escola deve assegurar, para além de uma função puramente pedagógica, uma função de legitimação dos saberes vernaculares que não deveria limitar-se ao domínio da linguagem, mas estender-se ao conjunto das práticas culturais. Entretanto, a julgar-se pelas práticas observadas em nossas situações de ensino, ainda persiste a legitimação de um único registro, que caminha junto com a legitimação de práticas sociais também consideradas como padrão, correspondentes a classes ou grupos sociais privilegiados.

5.2.4. Atividades que interrelacionem textos considerados literários canônicos, com textos literários não canônicos e com texto não literários

Apesar de ainda não ter efetuado tentativas desse gênero na intervenção da pesquisa, considera-se a possibilidade, através de um tema mais ou menos comum e do fenômeno da intertextualidade como um todo, de abordar os tipos de textos acima descritos, tanto em atividades de leitura como de produção. A vantagem de tal abordagem estará provavelmente em facultar a possibilidade de convivência com diferentes tipos de texto em contraste, observando as diferentes relações entre forma, sentido e elementos do discurso. ${ }^{10}$ Para uma visão mais aprofundada sobre o trabalho com o texto literário
na sala de aula, cf. neste mesmo número o artigo de Brandào. 
5.2.5. Atividades que integram a linguagem verbal e a linguagem não verbal

Dabène (1994: 160) sugere atividades translangagières ${ }^{11}$, que "têm por objetivo a aprendizagem da utilização da linguagem através de tarefas não langagières, mas que requerem, para sua execução, o recurso à linguagem: poderse-á suscitar, assim, a realização de objetos concretos (artísticos, técnicos ou utilitários), a partir de instruções de natureza verbal dadas aos alunos ou produzidas por eles". Mesmo acatando a sugestão de Dabène, é preciso ter cuidado para que a integração entre 0 texto lingüístico e 0 não lingüístico possa ser feita de forma que a primazia da linguagem não acabe tornando a atividade um exercício de "aplicação de linguagem", em que a realização desses "objetos" passe apenas a existir em função da aprendizagem do item lingüístico. Mais proveitosa ainda para a aprendizagem seria uma abordagem em que a integração fosse tal que se pudesse partir do não verbal para o verbal e vice-versa. Acrescente-se ainda que, além de "objetos", podem surgir outras alternativas: no domínio das artes, por exemplo, tem-se a produção teatral, a musical, incluindo dança, canto etc.

5.2.6. Atividades que integrem o ensino e a aprendizagem da língua às outras disciplinas do currículo

Citando Stern, Coste (1995: 79-93) defende uma concepção curricular mais abrangente para o ensino de línguas segundas, que é o curriculum multidimensional. Esse tipo de currículo ultrapassa os programas nocionais-funcionais e propõe quatro programas (syllabus) paralelos: um programa de língua, ao mesmo tempo gramatical formal e nocionalfuncional; um programa comunicativo/experiencial, do qual constam as relações motivadas e significantes com o meio físico e social, estabelecidas de forma singular, por meio da

"Translangagières" e "langagières": o francês faz diferença entre langagier, da linguagem ("linguageiro"), levando $\mathrm{em}$ conta fatores psicológicos, sociológicos, etnológicos etc. (Cf. Dictionnaire de Didactique des Langues), e linguistique (lingüístico). Por não existir termo eqüivalente em português. optou-se por deixá-los em francès neste texto. 
comunicação langagière, enquanto compreensão, produção e negociação; um programa de cultura, que adota um ponto de vista antropológico e sociológico; e um programa de formação langagière geral, que corresponde a conhecimentos gerais de linguagem, em três domínios de intervenção: a tomada de consciência lingüística, a tomada de consciência cultural e a tomada de consciência estratégica.

Em seguida, Coste (op. cit.: 90) retoma a noção de "código integrado" de Bernstein, oposto ao "código serial". Apesar das críticas, que se devem, segundo Coste, aos excessos de interpretação da proposta de Bernstein, a noção de "código integrado" permite conceber as transversalidades, as passagens entre o que está fora e o que está dentro da escola, como também entre as disciplinas. Como se pode observar, tal concepção já ultrapassa o quadro do ensino e aprendizagem de línguas e envolve o quadro geral da concepção de currículo escolar global, que passa a ser também multidimensional.

Entretanto, cabe salientar que, mais uma vez, o que se observa na prática de nossas instituições escolares ou é ainda uma concepção marcada por fronteiras entre saberes e disciplinas, ou então tenta-se aqui ou ali integrações, que muitas vezes não ultrapassam a iniciativa de um ou outro professor, ou quando efetuadas num plano institucional, essas tentativas são ainda pontuais e superficiais, não chegando a reformular a idéia de currículo serial que permanece marcante, mesmo nas instituições mais favorecidas. A integração entre os conhecimentos veiculados nas diferentes disciplinas através da leitura e produção de textos é, portanto, um campo a ser explorado, desde que os professores e a escola estejam preparados para executar essa integração, para que ela não venha apenas significar mais um "modismo" , sem muita conseqüência para a aprendizagem.

\section{REFLEXÕES FINAIS}

Após esse percurso rápido e necessariamente não exaustivo pelas teorias e práticas de leitura e produção de textos, e diante da recusa de recorrer ao receituário já 
explicitada na apresentação do número, é descabido apresentar posiçōes conclusivas que remetam a respostas acabadas. O que é possível concluir, após essas considerações, é principalmente a necessidade de se considerar o ensino e a aprendizagem da leitura e produção de textos em sua amplitude, superando as visões fragmentadas e fechadas em determinados modelos, ultrapassando o âmbito da sala de aula de língua, passando por outras disciplinas do currículo e indo além das fronteiras da instituição. Além disso, repetindo o que já vem sendo reivindicado por muitos em quase todas as áreas que focalizam de alguma forma o ensino e a aprendizagem, fica evidente a urgência de projetos de formação de professores e de reformulação das propostas institucionais que não se limitem a iniciativas pontuais de treinamento, para que se supere, nas diversas realidades de sala de aula, o estágio da simples aplicação de modelos ou técnicas.

\section{REFERÊNCIAS BIBLIOGRÁFICAS}

BAKHTIN, M. Marxismo e filosofia da linguagem. São Paulo: Hucitec, 1981.

CAVALCANTI, M. Interação leitor-texto: Aspectos de interpretação pragmática. São Paulo: Editora da UNICAMP,
1989. CERTEAU, M. de. A invenção do cotidiano. Petrópolis: Vozes,
1996.

CICUREL, F. Parole sur parole: le métalangage en classe de langue. Paris: Clé International, 1985. CICUREL, F. Lectures interactives en langue étrangère. Paris:
Hachette, 1991.

COSTE, D. Lecture et compétence de communication. Le Français dans le Monde. Paris: Hachette/Larousse, n. 141, p. 25-34, nov./déc. 1978. 
DABĖNE, L. Repères sociolinguistiques pour l'enseignement des langues. Paris: Hachette, 1994.

GALISSON, R.; COSTE, D. Dictionnaire de didactique des langues. Paris: Hachette, 1976.

GALISSOT, R. Au-delà du sujet philosophique et psychanalitique, au-delà du sujet historique: sujet, sujet collectif et théorie sociale. L'Homme et la Société. Paris: L'Harmattan, n. 101, p.49-55, 1991.

GERALDI, J. W. Portos de Passagem. São Paulo: Martins Fontes, 1991.

GREIMAS, A. J.; COURTÉS, J. Sémiotique: dictionnaire raisonné de la théorie du langage. Paris: Hachette, 1986. t.2.

KLEIMAN, A. Oficina de leitura: teoria e prática. Campinas: Pontes, 1992.

KRAMSCH, C. Interaction et discours dans la classe de langue. Paris, Hatier/Didier, 1991.

LAJOLO, M. Leitura-literatura: mais do que uma rima, menos do que uma solução. In: ZILBERMAN, R.; SILVA, E. T. da (Org.). Leitura: perspectivas interdisciplinares. São Paulo: Ática, 1998.

LANTZ, P. Sujet de la connaissance et de la subjectivité. L'Homme et la Société. Paris: L'Harmattan, n. 101, p. 49-55, 1991.

MAINGUENEAU, D. Les analyses du discours en France. Présentation. Langages. Paris: Laroussse, n. 117, p. 5-11, mars 1995.

MARCUSCHI, L. A. Concepção de língua falada nos manuais de português de $1^{\circ}$ e $2^{\circ}$ graus: uma visão crítica. Trabalhos em Lingüística Aplicada. Campinas: Editora da UNICAMP, n. 30, p.39-79, jul./dez.1997.

PÉRY-WOODLEY, M-P. Les écrits dans l'apprentissage: clés pour analyser les productions des apprenants. Paris: Hachette, 1993. 